\title{
EXTENSÃO UNIVERSITÁRIA E RESPONSABILIDADE SOCIAL: 20 ANOS DE EXPERIÊNCIA DE UMA INSTITUIÇÃO DE ENSINO SUPERIOR
}

\author{
Breno de Paula Andrade Cruz \\ Doutorando em Administração da Fundação Getúlio Vargas - Eaesp-FGV) \\ Professor da Universidade Federal Rural do Rio de Janeiro - UFRRJ \\ brenocruz@ufrrj.br
}

Willian dos Santos Melo

Mestre pela Escola Brasileira de Administração Pública e de Empresas - EBAPE/FGV william_santos_melo@yahoo.com.br

\section{Fernando César Benevenuto Malafaia}

Especialista em Auditoria Governamental pela Universidade do Tocantins - UNITINS fcmalafaia@gmail.com

\section{Fernando Guilherme Tenório}

Doutor em Engenharia de Produção pela Universidade Federal do Rio de Janeiro - UFRJ Professor da Escola Brasileira de Administração Pública e de Empresas - EBAPE/FGV fernando.tenorio@fgv.br

\begin{abstract}
RESUMO
Na lógica contemporânea, o conceito de responsabilidade tem conquistado seu espaço tanto na academia quanto na sociedade. Este trabalho utiliza o conceito de Responsabilidade Social a partir da Extensão Universitária, para discutir como que uma instituição de ensino superior contribui para a promoção da cidadania. O objetivo deste artigo é descrever uma experiência de extensão universitária implantada há 20 anos por alunos de mestrado e doutorado e que já capacitou mais de 800 moradores de comunidades ligadas à Arquidiocese do Rio de Janeiro para a elaboração, administração e avaliação de projetos comunitários. A pesquisa é do tipo qualitativa e tem como método a pesquisa-ação. Os resultados são divididos em três categorias: (i) benefícios para os participantes e sociedade; - capacitação e elaboração de projetos comunitários, integração e fortalecimento da comunidade; (ii) benefícios para os pesquisadores - experiência docente e pesquisa; e, (iii) benefícios para a instituição de ensino superior - pioneirismo do programa, financiamentos adquiridos e visibilidade na área.
\end{abstract}

Palavras-chave: Extensão universitária; Gestão social; Responsabilidade social; Transferência de tecnologia social.

\section{UNIVERSITY EXTENSION AND CORPORATE SOCIAL RESPONSIBILITY: 20 YEARS OF EXPERIENCE IN A BRAZILIAN UNIVERSITY}

\begin{abstract}
This article review claims about University Extension and Corporate Social Responsibility (CSR). The central point of this paper is to highlight the relationship between these too topics in a Brazilian university in Rio de Janeiro city and the society. In 20 years, more than 850 people from poverty areas in Rio de Janeiro were capacitated for working on social projects within their neighborhoods. This investigation is based in a qualitative view and the method used was action-research. The results of this experience are: a) benefits to society and all participants of the process, b) benefits to researchers and experience as teacher, and c) benefits for the university who started this process. Key words: Corporate social; Responsibility; Social management; Transfer of social technology; University extension.
\end{abstract}




\section{INTRODUÇÃO}

Ao longo dos últimos 30 anos, a sociedade brasileira passou por diversas mudanças políticas, econômicas, sociais e culturais. Uma das principais mudanças esteve relacionada ao ensino superior no país. A discussão antagônica sobre o papel da instituição de ensino superior (IES) tem sido evidenciada em diferentes áreas de conhecimento. De um lado, há a perspectiva filosófica da educação superior como instrumento propulsor do desenvolvimento social e técnico. De outro, a perspectiva quantitativa, com o aumento do número de cursos de graduação e pós-graduação.

Ao mesmo tempo, nesta lógica transformacional, de uma forma mimética (ou não), diversas empresas passaram a perceber a importância de práticas de Responsabilidade Social Corporativa (RSC) como uma estratégia de obtenção ou manutenção de vantagem competitiva. Entretanto, em muitos casos, a utilização de conceitos de RSC esteve e ainda está ligada ao assistencialismo ou com uma prática de promover uma imagem socialmente correta para os acionistas e sociedade.

Neste sentido, a abordagem de RSC, neste artigo, é construída a partir dos conceitos de Extensão Universitária e Transferência de Tecnologia Social e leva em consideração os benefícios para a IES, os participantes (alunos de mestrado e doutorado) e também para a sociedade. Por meio da extensão universitária, que é alicerçada no diálogo, é possível realizar o processo de transferência de tecnologia social, ou seja, o empoderamento das representações coletivas, por meio de instrumentos operacionais oriundos da administração.

A experiência relatada neste artigo é uma ação sistematizada criada há 20 anos com o objetivo de desenvolver alternativas para a solução de problemas sociais das comunidades, ao mesmo tempo em que visa complementar a formação de docentes, via processo dialógico, em que os educadores (com seus conhecimentos teóricos) e os cidadãos (com os seus saberes práticos adquiridos com as dificuldades vivenciadas) trocam suas experiências. Já foram capacitados mais de 850 moradores de distintas comunidades do município do Rio de Janeiro (RJ). As iniciativas buscam fomentar a ampliação da capacidade comunitária para intervir na sua própria realidade, gerando benefícios que podem ser compartilhados e reproduzidos em outras comunidades. Assim, considera-se esta experiência como uma aplicação concreta de gestão social.

Este artigo se torna relevante por algumas razões. A primeira delas diz respeito à sistematização de um trabalho que ocorre há 20 anos e que gera retornos intangíveis para as partes envolvidas. A segunda, é a publicação de uma experiência consolidada e que atende às atuais características do processo de ensino-aprendizagem de um gestor e que vai ao encontro da temática central da Revista Gestão Social e Ambiental. E, a terceira, é a preocupação dos pesquisadores que abordam a temática do ensino e pesquisa em Administração em discutir casos e métodos que possuem perspectivas metodológicas e epistemológicas coerentes com a realidade do educando, do educador e da instituição de ensino.

Esta primeira parte do artigo fez uma breve contextualização dos aspectos gerais do trabalho. A seguir são apresentados os conceitos de Extensão Universitária, Transferência de Tecnologia Social e Responsabilidade Social Corporativa. O item três apresenta as características gerais do programa em análise. $\mathrm{O}$ item seguinte discute a perspectiva metodológica do trabalho, evidenciando a perspectiva epistemológica e os sujeitos que participam desta experiência há 20 anos. O item cinco apresenta os principais resultados, e, por fim, o último item, reflexões sobre o processo.

\section{REFERENCIAL TEÓRICO}

A base teórica que auxilia na construção deste artigo e na concepção do programa está alicerçada numa perspectiva crítica, em que se leva em consideração o desenvolvimento do cidadão. A seguir, são descritos os conceitos de Extensão Universitária, Transferência de Tecnologia Social e Responsabilidade Social Corporativa. 


\subsection{O Sentido da Extensão Universitária}

O sentido do termo extensão foi devidamente avaliado e repensado pelos autores deste estudo. Só a partir da real compreensão do conceito extensão, é que se afirmou que o exemplo demonstrado nesse estudo vai ao encontro do enfoque defendido por Freire:

(...) o termo extensão, na acepção que nos interessa aqui [...] indica a ação de estender e de estender em sua regência sintática de verbo transitivo relativo, de dupla complementação -: estender algo $a$. Nesta acepção, quem estende, estende alguma coisa (objeto direto da ação verbal) $a$ ou até alguém (objeto indireto da ação verbal) - aquele que recebe o conteúdo do objeto da ação verbal (1971, p.20)

Pensar extensão universitária pressupõe também trabalhar o processo de formação universitária embasada em uma pedagogia crítica que facilite a construção de novos conhecimentos, percebendo o contexto social em que está inserido. Adotando essa posição, é possível fazer a interface entre o saber acadêmico e o popular, construindo assim uma relação de criticidade e de intercâmbio de experiências.

A abordagem de uma pedagogia crítica fundamenta-se na liberdade entre educador e educandos, em que o aprendizado se constrói de maneira bilateral: educador ensina e aprende ao mesmo tempo.

Educar e educar-se, na prática da liberdade, é tarefa daqueles que sabem que pouco sabem - por isto sabem que sabem algo e podem assim chegar a saber mais - em diálogo com aqueles que, quase sempre, pensam que nada sabem, para que estes, transformando seu pensar que nada sabem em saber que pouco sabem, possam igualmente saber mais" (Freire, 1971, p.25).

Dada a dimensão do artigo, não será abordado o levantamento histórico, sua gênese, importâncias e possíveis desdobramentos da extensão universitária. A ênfase é a de verificar a importância que a extensão universitária adquire e quais são ou deveriam ser seus principais pressupostos conceituais (seu sentido).

A extensão universitária está fortemente calcada no modelo conceitual da pedagogia crítica, que, por sua vez, está alicerçada no diálogo, que é uma relação horizontal, onde o professor e aluno são sujeitos que fazem e refazem a história. Ao se respeitar as experiências dos alunos por meio de um constante processo dialógico, as chances de um trabalho em contextos populares se tornam mais reais, já que a presente ação valoriza o contexto social na abordagem pedagógica realizada.

Autores como Boff (1986) já demonstram em suas obras a importância de a pessoa ou de o agente que vai trabalhar com o povo e que, desempenhando uma função pedagógica, tem como finalidade essencial, reforçar o poder do povo rumo à autonomia, isto é, a de tornar o aprendiz, como sujeito ativo de sua própria história.

Freire (2007) reforça ainda mais essa assertiva e a amplia, quando expõe que o ato de educar também apresenta um caráter eminentemente político, uma forma de intervenção no mundo. Segundo ele, “(...) formar é muito mais do que puramente treinar o educando no desempenho de destrezas" (Freire, 2007, p.14). Para o pedagogo pernambucano, o educador deve sempre estimular a capacidade crítica do educando, sua curiosidade, sua insubmissão.

A extensão universitária tem como um de seus objetivos, possibilitar a passagem da "consciência ingênua" para a "consciência crítica". Para isso, o educador tem que estabelecer uma relação de igualdade com seus educandos, suas ações e suas práticas têm que ser pautadas a partir do contexto social, sendo indispensável ao educador/agente entrar em contato participante com a vida do povo com o qual está trabalhando. Para isso, o educador/agente dispõe de variados tipos de formas e meios para inserir-se na comunidade, como, por exemplo: contato constante (organicidade), participação regular; moradia; trabalho e cultura. A inserção real do 
educador/agente evita o autoritarismo ou as relações de dominação no exercício da prática pedagógica (Boff, 1986).

Pode-se inferir que qualquer esforço para práticas bem-sucedidas de extensão universitária, esteja ou não associado a uma capacitação profissional - seja ela em qualquer campo do conhecimento - o objetivo fundamental é possibilitar a "[...]problematização do homem-mundo ou do homem em suas relações com o mundo e com os homens, possibilitar que estes aprofundem sua tomada de consciência da realidade na qual e com a qual estão" (Freire, 1971, p.33).

A extensão universitária apresenta uma importância crucial para o desenvolvimento do homem como indivíduo ativo, que transforma seu mundo e que estabelece uma relação com o mundo em que está inserido. Por outro lado, a extensão universitária permite aos mais abastados, seja de conhecimento ou de renda, a real conscientização de seu mundo e dos indivíduos que coabitam um mesmo espaço social. Ou seja, a extensão universitária permite reconhecer diferenças respeitando-as, aprender experiências, ensinamentos e diferentes mundos sociais, conforme destacado no trecho a seguir:

(...) a extensão tem como princípios integradores o ensino-pesquisa, a teoria e prática como função acadêmica da universidade que acabam por revelar um novo pensar e fazer, que se consubstancia em uma postura de organização e intervenção na realidade, em que a comunidade deixa de ser passiva no recebimento das informações/conhecimentos transmitidos pela universidade e passa a ser, participativa, crítica e construtora dos possíveis modos de organização e cidadania. A confirmação da extensão como função acadêmica da universidade não passa apenas pelo estabelecimento da interação ensino e pesquisa, mas implica a sua inserção na formação do aluno, do professor e da sociedade, na composição de um projeto políticopedagógico de universidade e sociedade em que a crítica e autonomia sejam os pilares da formação e da produção do conhecimento (Jezine, 2004, p.03).

No exemplo demonstrado nesse artigo, analisa-se a intenção/ação do enfoque a ser trabalhada com os educandos e se pauta nas conceituações defendidas pelos autores apresentados. Entretanto, a experiência analisada não é prioritariamente um espaço para o exercício da participação e do alcance de uma autonomia plena, de tal sorte que sua dinâmica - metodologia e atuação dos educadores - fica limitada a realizar uma prática de ensino mais voltada à transferência de tecnologia social.

Talvez resida aí a explicação para o modelo de extensão exemplificada neste trabalho ser mais condizente com os ensinamentos de Freire do que com os de Boff. Tratando-se de um espaço de transferência de tecnologia social, uma pedagogia voltada para a educação, focada mais na relação educador-educando, ganha mais destaque do que uma pedagogia voltada para o trabalho com o povo rumo a sua plena emancipação, focada mais na relação agente externo - comunidade.

\subsection{Transferência de Tecnologia Social}

O conceito de tecnologia social aqui adotado foi desenvolvido pelo Instituto de Tecnologia Social (ITS) da Fundação Banco do Brasil ao longo do ano de 2004 e diz respeito ao "[...] conjunto de técnicas e metodologias transformadoras, desenvolvidas e/ou aplicadas na interação com a população e apropriadas por ela, que representam soluções para inclusão social e melhoria das condições de vida" i.

Um dos resultados do processo de extensão universitária é a transferência de tecnologia social. Neste sentido, o Instituto de Tecnologia Social (ITS) tem como um de seus objetivos, difundir esse novo conceito. Uma de suas abordagens é que as tecnologias sociais (TSs) devem ser compreendidas como um conjunto de idéias, ações, técnicas e metodologias que transformam uma 
população e quando aplicadas, de maneira que a população possa interagir, podem representar soluções para a inclusão social e também na melhoria de vida daquela população (ITS, 2004, p. 130).

Bava (2004) afirma que as tecnologias sociais podem ser consideradas como métodos e técnicas que estimulam processos de empoderamento das representações coletivas da cidadania, de forma a capacitá-las a lutar nos espaços públicos por alternativas inovadoras orientadas para a defesa dos interesses das maiorias e pela distribuição de renda. Tais características estão presentes em ambas as definições apresentadas pela Rede de Tecnologia Social (RTS,2006) e pelo ITS.

Quanto mais informação se tem sobre a existência de novas técnicas, suas condições de uso e seus eventuais riscos, mais aumenta a complexa formação social crítica e de direcionamento para novos caminhos a fim de atender diversificadas necessidades sociais (Figueiredo, 1989).

Rodrigues e Barbieri (2008) apontam que o processo de produção de tecnologia social deve, prioritariamente, ser voltado para a emancipação dos atores envolvidos, que são, principalmente, os próprios produtores e usuários dessas tecnologias. Assim, as soluções são construídas coletivamente pelos principais beneficiados, diferentemente de soluções importadas ou produzidas por equipes especialistas.

De acordo com a dimensão ideológica da tecnologia, esta se apresenta como um processo neutro, de domínio e controle da natureza em benefício de todos. Apesar de a tecnologia poder se apresentar de forma unidirecionada, jamais deveria se apresentar assim, uma vez que é um processo condicionado pela complexidade social dos contextos em que é produzida e aplicada. Mesmo que orientada pela hegemonia de alguns grupos, a pluralidade dos interesses sociais é a primeira forma de se garantir a diversidade e os avanços tecnológicos (Figueiredo, 1989).

Independente de suporte técnico de instituições de fomento, qualquer pessoa ou organização local pode identificar tecnologias ou processos produtivos que sejam capazes de, criativamente, utilizar os recursos existentes e subutilizados. "Gerar a ampla acessibilidade dos conhecimentos acumulados sobre tecnologias sociais constitui um fator importante de dinamização" (Dowbor, 2005, p.194).

Dessa forma, as informações recebidas sobre tecnologias disponíveis são diversamente captadas e adaptadas às experiências específicas dos diferentes sujeitos sociais. Assim, o entendimento da tecnologia é desigual e as condições para que esta seja adotada também não são as mesmas, seja pela forma de captação de seu significado e dos seus efeitos produzidos, como também pelas oportunidades econômicas de financiamento de sua absorção (Figueiredo, 1989).

A fim de facilitar a compreensão da tecnologia, a TS pode ser expressa em dois planos: o conceitual e o material, e, é na interação entre esses dois planos, que ela se desenvolve. No plano conceitual, é proposta por meio da TS, uma alternativa de intervenção na sociedade, em que ocorra, de forma participativa, a construção do conhecimento, da ciência e tecnologia. No plano conceitual, a TS representa uma intervenção social que é inclusiva em todos os momentos. Já no plano material, a TS é aplicada pelas experiências na construção de soluções para questões sociais variadas, de acordo com as possibilidades e as limitações de cada grupo. São nestas experiências que é comprovada a viabilidade e eficácia da tecnologia social, enquanto conceito, e é estabelecida uma nova concepção de intervenção social (RTS, 2006).

Segundo a RTS (2006, p.16) “[...]apesar da existência desses dois planos, a idéia de TS (plano conceitual) é geralmente percebida de forma intuitiva. A maior parte das pessoas não chega ao tema pelo caminho da reflexão teórica, mas a partir da vivência e/ou sensibilização para o tema da exclusão social; chega em busca de ações que possam promover a inclusão por meio da aplicação do conhecimento científico-tecnológico".

Na tecnologia social não há apropriação exclusiva de conhecimentos, pois é necessário tornálos acessíveis aos outros grupos com problemas parecidos e também devido à sua forma de produção, que consiste em um processo participativo. Por isso, esses conhecimentos são transmitidos entre os agentes envolvidos na sua produção e utilização e disponibilizados em redes 
para sua difusão (Rodrigues e Barbieri, 2008). Para Dagnino (2004, p.194), a tecnologia social deve apresentar algumas características. Segundo o autor:

Ela deve ser adaptada ao reduzido tamanho físico e financeiro; nãodiscriminatória; liberada da diferenciação (disfuncional, anacrônica e prejudicial nos ambientes autogestionários) entre patrão e empregado; orientada para um mercado interno de massa; libertadora do potencial e da criatividade do produtor direto. Resumindo, deve ser capaz de viabilizar economicamente os empreendimentos autogestionário.

O ITS propõe a reflexão sobre o conceito de TS a partir de princípios, parâmetros e implicações. Em relação aos princípios, são destacados: a aprendizagem e participação, enquanto processos que caminham juntos; a transformação social, que implica na compreensão da realidade de maneira sistêmica; e a transformação social, que ocorre enquanto existe o respeito às identidades locais e compreensão de que qualquer indivíduo é capaz de gerar conhecimento e aprender (ITS, 2004).

As implicações do conceito são organizadas em três grandes eixos: o primeiro, trata da relação entre a sociedade e a produção de conhecimento e tecnologia; o segundo, de como a produção de conhecimento é direcionada, e terceiro, de um modo específico de fazer intervenção na realidade, que está ligado tanto aos parâmetros que caracterizam o processo de intervenção quanto aos resultados esperados (ITS, 2004).

\subsection{Responsabilidade social}

Há no exemplo demonstrado neste trabalho, características que ora demonstram seu caráter extensionista, e ora um caráter de responsabilidade social corporativa para com a coletividade de um modo geral. Uma atuação socialmente responsável, em muitos casos, é confundida com práticas assistencialistas ou filantrópicas. Ao buscar um compromisso com a sociedade, algumas organizações se condicionam a ações assistencialistas ou filantrópicas, o que impede, em muitos casos, o real crescimento e desenvolvimento de um grupo.

A sociedade, de uma forma geral, tem se mobilizado para atender as carências das populações periféricas (Barbosa, 2007). O filantropismo é entendido como a prática de fazer, no ambiente empresarial, o bem a um determinado grupo associada à caridade. Geralmente, a principal característica da filantropia é a ação estratégica, uma vez que tem a publicidade como pano de fundo. De acordo com Duprat 1993 apud Sanglard (2003), uma ação filantrópica é estratégica porque provoca a visibilidade de uma ação realizada por um grupo e acirra a concorrência entre os agentes que realizaram a ação.

Por sua vez, o assistencialismo no Brasil, é a prática de resolver alguns problemas pontuais de ordem econômica. Isso cria a dependência real de quem é assistido com a parte que assiste (Barbosa, 2007). Numa perspectiva crítica, Ramminger (2001) considera que ações assistencialistas são prejudiciais ao desenvolvimento de uma comunidade periférica. Ao solucionar problemas com agilidade, não se aborda as raízes deste problema e o agente assistencialista (ou gestor) se autoavalia como um socialmente responsável. O trecho abaixo destaca essa autopercepção.

Nos regozijamos com nossa bondade e solidariedade. Até os tratamos de igual para igual, não é mesmo? Somos como gênios da lâmpada: "Faça seu pedido e ele será satisfeito!!!" E eles pedem. Pedem comida, roupas, passagens de ônibus, consultas em hospital, remédios, dinheiro... [...] $\mathrm{O}$ assistencialismo é sempre uma política de exclusão que retro-alimenta a miséria (RAMMINGER, 2001, p.42-43). 
Conforme destacado por Ramminger (2001) no trecho anterior, várias são as carências, e o assistencialismo sempre deixará de levar a um bom resultado de longo prazo, pois, as ações são pontuais. Identificar as carências de uma comunidade é essencial, entretanto, isso não significa que uma postura de resolução destas carências seja adotada por uma empresa.

De acordo com Bhattacharyya et al (2008), a Responsabilidade Social Empresarial (RSE) deve resgatar a dinâmica do relacionamento entre a sociedade e os negócios da empresa (Davis et al, 1998 apud Bhattacharyya et al, 2008). Em resumo, em uma organização, esta estratégia, quando adotada, deve estabelecer uma relação de ganhos para a organização e para a sociedade, por meio da busca contínua de sustentabilidade para estes dois grupos ao longo do tempo.

É fato que atitudes responsáveis por parte das empresas pode incrementar as vendas de produtos ou serviços e abrir novos mercados (Heslin e Uchoa, 2008). O engajamento de uma empresa em questões ambientais e sociais contribui também para o posicionamento da empresa em um determinado nicho e também no posicionamento de sua marca. Este engajamento, em muitos casos, confunde-se com o assistencialismo a partir do momento que se busca consolidar uma imagem ou reputação diante dos interessados. Uma orientação socialmente responsável, em muitos casos, é confundida com práticas assistencialistas ou filantrópicas. Ao buscar um compromisso com a sociedade, especificamente com stakeholders que exercem algum tipo de pressão que pode ser negativa para uma empresa, algumas empresas atuam de forma assistencialista ou filantrópica.

Mujih (2007) corrobora para uma perspectiva diferente do debate sobre a responsabilidade social. Para o autor, a responsabilidade social empresarial pode se apresentar por meio de dois modelos na busca da sobrevivência da empresa. Estes modelos são os de punição e de conformidade - que não estão alinhados à proposta deste artigo. No que diz respeito ao modelo de punição, Mujih (2007) destaca que existem fortes penalidades legais para empresas que violam algumas regras. Já no modelo de conformidade, o autor destaca a ênfase dada na relação estabelecida entre a empresa e os agentes reguladores.

Quando relacionado à área de Administração, o desenvolvimento sustentável deve ser entendido como um conceito amplo e que engloba diversos atores, o que o faz sistêmico, assim como a RSE. De acordo com Muschett (1997), o termo desenvolvimento sustentável era pouco conhecido antes da Conferência Mundial de 1992 no Rio de Janeiro. A partir da Eco 92 houve um crescimento exponencial rápido do uso deste termo tanto por organizações do terceiro setor e empresas quanto pela comunidade acadêmica e grupos ambientais. Para o autor, ao se analisar desenvolvimento sustentável, é necessário destacar alguns elementos essenciais que se traduzam em questões relativas às gerações presentes e futuras, como: estabilização do crescimento da população; transferência de tecnologias e novas tecnologias; eficiência no uso de recursos naturais; redução e prevenção da poluição; determinação de limites ambientais; estabelecimento de relações de ganhos, tanto o meio ambiente quanto a sociedade e as empresas têm ganhos simultâneos; educação; e, mudanças sociais e culturais. A proposta em análise neste artigo evidencia os ganhos para a sociedade (educandos e educados) e também para a instituição de ensino.

\section{O PROGRAMA GESTÃo DE PROJETOS COMUNITÁRIOS}

O Programa Gestão de Projetos Comunitários é uma ação sistematizada e implementada há 20 anos com o objetivo de desenvolver alternativas para a solução de problemas sociais em comunidades periféricas, ao mesmo tempo em que visa complementar a formação de futuros docentes, via processo dialógico, em que os educadores, com seus conhecimentos teóricos, e os cidadãos, com os seus saberes práticos adquiridos com as dificuldades vivenciadas, trocam suas experiências. No ano de 2010, a disciplina de mestrado, que era eletiva, se transformou em disciplina obrigatória no curso de mestrado acadêmico da IES analisada.

O referido programa acadêmico vem sendo realizado há 20 anos, por meio de uma parceria entre a academia e as comunidades assistidas pelas pastorais vinculadas à Arquidiocese do Rio de 
Janeiro. Esta experiência, da qual participaram cerca de 850 moradores das diferentes comunidades assistidas, envolveu cerca de 100 alunos matriculados nos cursos de graduação, mestrado e doutorado da instituição de ensino durante sua trajetória desde 1990.

As iniciativas buscam fomentar a ampliação da capacidade comunitária para intervir na sua própria realidade social, gerando benefícios que podem ser compartilhados e reproduzidos em outras comunidades. Assim, considera-se como aplicação concreta de práticas em gestão social. Os objetivos finais do programa são: (a) a formação de docentes a partir de experiências concretas; (b) a possibilidade de proporcionar a aplicação de conhecimentos teóricos adquiridos em sala de aula; e, (c) o atendimento de demandas das comunidades na gestão comunitária de seus projetos, com transferência de conhecimentos em elaboração, administração e avaliação de projetos.

Do início do programa ( $1^{\mathrm{a}}$ fase) ao término ( $3^{\mathrm{a}}$ fase) são 18 meses, o que equivale a três semestres letivos - um semestre para cada módulo. Neste sentido, a transferência de tecnologia social ocorre da seguinte maneira:

I - Elaboração de Projetos Comunitários - conjunto de atividades com ações concretas visando atender às necessidades previamente identificadas pelas comunidades participantes. Esta fase é dividida em quatro etapas: identificação, viabilidade, projeto e análise.

II - Administração de Projetos Comunitários - atividades abrangentes e integradas para controle dos recursos presentes em qualquer projeto: recursos humanos, materiais e financeiros.

III - Avaliação de Projetos Comunitários $-\mathrm{Na} 1^{\mathrm{a}}$ fase, Elaboração, observa-se o futuro, na $2^{\mathrm{a}}$ fase, a Administração, o foco é no presente. Nesta $3^{\mathrm{a}}$ fase, Avaliação, discute-se o passado, comparando-se a análise feita ao término da elaboração, o acompanhamento da fase de execução e a avaliação final, propriamente dita (última etapa no processo de avaliação) que revisa todo o trabalho para verificar $\mathbf{0}$ alcance de objetivos e soluções dadas aos problemas, identificados na $1^{\mathrm{a}}$ fase.

\section{ASPECTOS METODOLÓGICOS}

Este item do artigo apresenta alguns aspectos metodológicos que permitem construir, ao longo de 20 anos, a extensão como forma de atuação em responsabilidade social de uma instituição de ensino que atua na graduação e pós-graduação (stricto sensu) na cidade do Rio de Janeiro (RJ). Assim, abaixo, são apresentados a perspectiva de pesquisa (qualitativa), o método de pesquisa (pesquisa-ação) e o processo de transferência de tecnologia social e seus atores.

\subsection{Perspectiva metodológica e método de pesquisa}

Este trabalho tem como perspectiva a pesquisa qualitativa, pois o processo de transferência de tecnologia social está embasado epistemologicamente em fundamentos não cartesianos e que valorizam a interação entre as partes envolvidas e o aprofundamento em questões sociais. Em sua definição conceitual, Vieira (2004) caracteriza e comenta as riquezas dos resultados da pesquisa desse tipo:

(...) se fundamenta principalmente em análises qualitativas, caracterizandose, em princípio, pela não utilização de instrumental estatístico na análise dos dados e (...) ela geralmente oferece descrições ricas e bem fundamentadas, além de explicações sobre processos em contextos locais identificáveis (p. 17-18).

Sob esta perspectiva, o método de pesquisa utilizado foi a pesquisa-ação, que tem, como principal contribuição, a dinâmica de tomada de decisão no processo de ação planejada e se tornou pertinente nesta experiência a partir do processo de transferência de tecnologia social. A pesquisaação é, principalmente, uma modalidade de intervenção coletiva, inspirada nas técnicas de tomada de decisão, que associa atores e pesquisadores em procedimentos conjuntos de ação com vista a 
melhorar uma situação precisa, avaliada com base em conhecimentos sistemáticos de seu estado inicial e apreciada com base em uma formulação compartilhada de objetivos de mudança.

A utilização da pesquisa-ação é explicada pelo fato de os pesquisadores detectarem problemas em seus ambientes de pesquisa e construírem com outros atores uma solução, adquirindo assim, um conhecimento sistemático sobre a situação identificada (Dionne, 2007). Para Vergara (2009), este método de pesquisa é um tipo particular de pesquisa participante (não se esgota na figura do pesquisador e tomam parte pessoas implicadas no problema sob investigação) e de pesquisa aplicada (motivada em resolver problemas concretos de finalidade prática) que supõe intervenção participativa na realidade social. Ou seja, é de natureza intervencionista.

Já Thiollent (1996, p.14) define a pesquisa-ação como “(...) um tipo de pesquisa social com base empírica que é concebida e realizada em estreita associação com uma ação ou com a resolução de um problema coletivo e no qual os pesquisadores e os participantes representativos da situação ou do problema estão envolvidos de modo cooperativo ou participativo".

Indo ao encontro do processo de transferência de tecnologia social, Morin (2004) entende a pesquisa-ação como uma démarche de compreensão e de explicação da práxis dos grupos sociais, pela implicação dos próprios grupos, e com intenção de melhorar suas práticas. No entanto tem ainda, a pesquisa-ação, objetivo emancipatório e transformador do discurso, das condutas e das relações sociais. Vai além da abordagem Lewiniana e exige que os pesquisadores se impliquem como atores. Assim, a pesquisa-ação está sempre ligada a uma ação que a precede ou a engloba e que a enraíza em uma história ou contexto.

Assim, o processo de pesquisa-ação ocorreu a partir das seguintes indagações: Como ensinar e conhecer uma realidade ao mesmo tempo? Uma vez conhecida essa realidade, como realizar uma intervenção nela? A ação educativa só se justifica com o envolvimento da comunidade e sua orientação para as possíveis soluções de problemas comunitários. Uma ação que considere como necessidade a participação das pessoas no processo de mudanças. Contudo, que formas podem ser utilizadas para efetivá-la? Além disso, essa ação educativa, determinada pelo conhecimento da realidade, não pode ser somente sinônima de transferência de conhecimento e sim ato dinâmico e permanente no processo de sua descoberta. Enfim, chegou-se à metodologia de pesquisa-ação para atender às expectativas de participação social dessa comunidade.

\subsection{O processo de transferência de tecnologia social e seus atores}

Baseado no conceito de transferência de tecnologia social, alunos de mestrado e doutorado da instituição em análise, com apoio de graduandos, promovendo a chamada extensão universitária, participaram desta transferência tecnológica para membros das comunidades assistidas pelas pastorais vinculadas à Arquidiocese do Rio de Janeiro.

\subsubsection{Perspectivas epistemológicas que norteiam o processo}

A preparação para o campo de pesquisa (interação social na perspectiva do educador) e ação (transferência de tecnologia social) foram fundamentadas a partir de três linhas de ação: (i) a racionalidade comunicativa - direcionando o escopo de toda proposta; (ii) a perspectiva pedagógica; e, (iii) os fundamentos técnicos em gestão de projetos comunitários.

Assim, para a primeira linha de ação, a racionalidade comunicativa, de Jürgen Habermas (1995), evidencia elementos conceituais da democracia deliberativa nas relações sociais contemporâneas.

No que diz respeito à perspectiva pedagógica, as obras 'Autonomia da Pedagogia' e 'Conscientização: teoria e prática da libertação', do educador Paulo Freire, foram utilizadas na preparação dos pesquisadores (alunos de mestrado e doutorado) para o contato com o campo de pesquisa e de ação, pois, a abordagem concebida por Freire, evidencia aspectos como o respeito ao 
educando e a construção do conhecimento a partir da interação (não autoritária) das partes envolvidas na relação ensino-aprendizagem.

A terceira linha de ação, a abordagem técnica-conceitual, foi construída a partir dos livros Gestão Social e Administração de Projetos Comunitários. Este último livro apresenta as áreas de Administração de Materiais, Gestão de Recursos Humanos e Administração Financeira, sendo todo o conteúdo da publicação elaborada com o objetivo de atender as especificidades de projetos comunitários.

\subsubsection{As características do público envolvido - pesquisadores e participantes}

\subsubsection{Pesquisadores}

Os pesquisadores envolvidos na elaboração e execução do programa sempre são alunos de mestrado (acadêmico e profissional), do curso de doutorado e de graduação. Estes pesquisadores são orientados por um professor da instituição que explica a trajetória do programa desde 1990 e discute a parte epistemológica anteriormente à ida ao campo. $\mathrm{O}$ processo de conhecimento e exploração do campo de pesquisa é sempre acompanhado por uma equipe de coordenadores (o professor e mais dois ex-alunos voluntários que se prontificam a dar continuidade ao projeto). Uma das características dos pesquisadores é a ausência de experiência prévia em sala de aula, o que permite um aprendizado para este grupo.

\subsubsection{Participantes}

Os participantes são, em sua maioria, pessoas oriundas de comunidades periféricas que estabelecem alguma relação com as pastorais interligadas à Arquidiocese do Rio de Janeiro. O único requisito exigido para frequentar as aulas é ser alfabetizado, não há restrição por gênero, raça, faixa etária, classe social ou escolha religiosa - mesmo as aulas sendo ministradas em um espaço estritamente católico, pessoas de orientação evangélica têm participado da experiência. Ou seja, o que move as pessoas a se inscreverem nos cursos (Elaboração de Projetos Comunitários, Administração de Projetos Comunitários e Avaliação de Projetos Comunitários), é a vontade de apreender novos conhecimentos para a mudança de suas realidades - já que os cursos ministrados, por alunos da IES, têm como objetivo construir com os educandos conhecimentos relativos à elaboração de projetos sociais em áreas periféricas do município do Rio de Janeiro.

\subsubsection{Parceiros}

A principal parceira da IES é a Cáritas Arquidiocesana do Rio de Janeiro que há 20 anos fornece o espaço físico e logístico para as aulas serem ministradas, contribuindo com parte do material didático e controlando a frequência dos alunos.

\section{RESULTADOS ALCANÇADOS}

Esta parte do trabalho apresenta os resultados obtidos ao longo dos 20 anos desta prática. Especificamente, são apresentados resultados para os participantes e sociedade, para os pesquisadores e a instituição de ensino superior. É explícita a visão de que todas as partes envolvidas se beneficiam com a execução deste projeto.

\subsection{Participantes e sociedade}

Este projeto visa a promoção da extensão universitária, uma vez que, é a ação de IES junto às comunidades, que disponibiliza ao público externo determinados conhecimentos por meio do desenvolvimento de ensino e pesquisa. Pelo contato direto entre membros da IES e da sociedade 
onde ela esta inserida, que se dá a transformação da realidade social local, ao mesmo tempo em que amplia a formação de seus alunos.

O conhecimento proporcionado sobre capacitação para elaboração de projetos comunitários aos membros das diversas comunidades leva a identificação de demandas e/ou problemas, a análise da viabilidade do projeto e a definição do projeto que será planejado e, possivelmente, executado.

A capacitação para a administração de projetos comunitários propõe demonstrar a importância da administração destes recursos, buscando manter o grau de motivação existente quando da elaboração do projeto. Aqui se busca ainda o envolvimento e comprometimento de membros da comunidade como elemento fundamental para o sucesso do projeto. A extensão é indissociável do ensino e da pesquisa, elas se complementam, na medida em que fornece material para a pesquisa e campo para o ensino, mas além disto ela forma cidadãos.

Os envolvidos são capacitados e informados da importância da avaliação do projeto comunitário, e aprendem a analisá-lo tanto a partir da ótica do formulador quanto da ótica das agências financiadoras. Assim, a comunidade ficaria apta a se credenciar a novos financiamentos de diversos outros projetos.

A promoção de articulação entre membros da comunidade em torno de um projeto comum fortalece a articulação dos membros da comunidade, observando-se um envolvimento maior do conjunto da cidadania daquele espaço urbano em processos decisórios para a busca da solução de problemas comuns.

Integração e fortalecimento de atividades de cada comunidade, presentes nos projetos apresentados, requerem uma sinergia entre os membros da comunidade envolvida para a obtenção do sucesso pretendido. Assim, as atividades de cada comunidade saem fortalecidas.

Articulação e dinamização de projetos comunitários transformam os membros das comunidades envolvidas em empreendedores que passam a articular e dinamizar as ações em prol da comunidade.

Promoção de encontros e trocas de experiências é, sem dúvida, outro fator de destaque. Entre os resultados obtidos, destaca-se a troca de experiências que acontece nos encontros entre os membros de diversas comunidades. Estes encontros fortalecem o convívio com membros de outros bairros e a promoção de projetos de sucesso que acabam por servir como estímulos para os iniciantes.

Importância da ação coletiva: leva ao reconhecimento da importância da ação comunitária para o desenvolvimento das consciências individuais. Ocorre a substituição do "EU” pelo "NÓS", a alteridade sempre presente no processo de ensino-aprendizagem.

\subsection{Pesquisadores}

Geralmente os alunos de mestrado têm seus primeiros contatos como docentes no término do curso. Na IES em causa, os estágios docentes para mestrandos com alunos de graduação não são obrigatórios. Logo, a experiência possibilita a vivência da prática docente. Mais que isso, esta prática é construída a partir da teoria crítica em Educação (Paulo Freire). Diversos ex-alunos participam da ideia de aprendizagem docente e na vida pessoal a partir de suas atuações como docentes.

As experiências da pesquisa-ação nestes 20 anos de projeto possibilitaram um amplo material de análise para os alunos. Seja numa perspectiva metodológica, prática ou epistemológica, diversos artigos foram publicados em congressos e periódicos, além de cinco livros que apresentam as práticas de elaboração, gestão e avaliação de projetos comunitários.

A visão aproximada da realidade contribui para pensar de forma diferente a elaboração de políticas públicas. Alguns alunos que já passaram por esta experiência na IES, estão atualmente em posições estratégias na esfera pública no que diz respeito à elaboração de políticas públicas. Vários 
são os relatos de ex-alunos que hoje informam que ter participado destas práticas contribuiu para que passassem a pensar, de forma sistemática e real, a respeito das necessidades da sociedade.

\subsection{Instituição}

Depois de 20 anos de experiência, esta disciplina atualmente faz parte da estrutura curricular obrigatória do curso de Mestrado em Administração Pública. A experiência inicial e voluntária se transformou no principal programa de extensão universitária da instituição. Os relatos e as experiências passadas serviam de motivação para os alunos ainda não matriculados se matricularem na disciplina eletiva. Após 20 anos, a instituição legitimou a experiência junto à estrutura curricular e revê as questões ligadas à Administração Pública e que permeiam projetos comunitários como forma de alcance da sustentabilidade territorial.

Alguns projetos obtiveram destaque em nível local e, por algumas vezes, seus representantes foram convidados a participar de entrevistas em rádios e de telejornais de massa no estado do Rio de Janeiro. A instituição foi citada por diversas vezes pelo processo de capacitação e desenvolvimento sustentável daqueles grupos tendo como base os depoimentos dos membros das comunidades atendidas. Estes relatos reforçam a reputação da IES para os atores diretos e indiretos que mantêm algum tipo de contato a instituição.

O programa ganhou visibilidade local a partir do seu quinto ano de experiência. Alunos de outras instituições no Rio de Janeiro (RJ) de programas de mestrado ou doutorado de áreas afins, começaram a se inscrever para cursar a disciplina e trocar experiências. A partir da publicação das experiências e do fortalecimento do grupo de pesquisa formado a partir desta temática, alunos de outros programas de estados como São Paulo e Minas Gerais começaram também a participar das experiências do programa.

A instituição gerencia um PRO-ADM na perspectiva da Gestão Social. Este projeto viabiliza a consolidação de uma rede capaz de atuar localmente, em um processo amplo de transformação, no qual a participação coletiva liga sujeito e objeto de estudo. Financiado pela Coordenação de Aperfeiçoamento de Pessoal de Nível Superior (Capes), o intuito não é desenvolver a formação mecanicista do administrador, mas sim promover o bem comum.

\section{CONSIDERAÇÕES FINAIS}

Ao longo da experiência com os mais de 850 participantes capacitados, foi promovido o desenvolvimento de diversas competências comunitárias e técnicas dos grupos envolvidos. $\mathrm{O}$ planejamento e a administração de projetos comunitários proporcionaram tanto aos membros quanto às comunidades envolvidas oportunidades para que possam alcançar melhorias na qualidade de vida, proporcionando-lhes, inclusive, um aumento na autoestima e retorno financeiro.

Neste processo, o ensino-aprendizagem, que envolve educandos e educadores, a permanência destas práticas ao longo destes 20 anos evidencia sua efetividade nas comunidades no que diz respeito ao processo de transferência de tecnologia social, uma vez que nunca houve qualquer tipo de divulgação que não seja aquela realizada pelos membros das comunidades (processo de divulgação "boca a boca"). A manutenção e a expansão deste tipo de experiência também é legitimada pela sua inserção na estrutura curricular de um curso de Mestrado em Administração Pública.

Em resposta à demanda dos membros das comunidades por este tipo de ação, a Arquidiocese do Rio de Janeiro lançou o "Curso de Formação Política e Cidadania”, com o objetivo de capacitar lideranças comunitárias para atuarem junto aos Conselhos Municipais, uma vez que estes conselhos têm se mostrado como importantes espaços na promoção do bem comum.

Por fim, como resultado deste processo, há a responsabilidade da instituição em gerir um projeto do PRO-ADM, financiado pela Capes na vertente da gestão social. Assim, a experiência apresentada parece contribuir para gerar e ampliar a discussão sobre temas relativos à cidadania 
deliberativa, gestão social e projetos comunitários. O apoio dado pelo edital Capes, demonstra a importância desta experiência para o desenvolvimento de comunidades periféricas e de competências sociais requeridas de um futuro gestor.

\section{REFERÊNCIAS}

Barbosa, I. M. da S. P. (2007) Sociedade civil brasileira: ação, articulação e mobilização. In: Revista Terceiro Setor, 1(1), 34-38.

Bava, S. C. (2004) Tecnologia social e desenvolvimento local. In: Fundação Banco do Brasil, Tecnologia social: uma estratégia para o desenvolvimento, Rio de Janeiro: Banco do Brasil.

Bhattacharyya, S. S., Sahay, A., Arora, A. P. E Chatuverdi, A.(2008) A toolkit for designing firm level strategic corporate social responsibility (CSR) initiatives. In: Social Responsibility Journal, 4(3), 265-282.

Boff, C.(1986) Como trabalhar com o povo: metodologia do trabalho popular. Petrópolis: Vozes.

Dagnino, R.(2004) A tecnologia social e seus desafios. In: Fundação Banco do Brasil, Tecnologia social: uma estratégia para o desenvolvimento, Rio de Janeiro.

Dionne, H. (2007) A pesquisa ação para o desenvolvimento local. Trad. Michael Thiollent. Brasília: Liber, 2007.

Dowbor, L (mai-ago/2005). Redes de apoio ao empreendedorismo e tecnologias sociais. Revista Brasileira de Gestão e Desenvolvimento Regional. São Paulo, 1(2), 83-108.

Figueiredo, V.(1989) Produção social da tecnologia. São Paulo: EPU.

Freire, P.(1980) Conscientização: teoria e prática da libertação. São Paulo: Moraes.

. (2007) Pedagogia da autonomia: saberes necessários à prática educativa. São Paulo: Paz e Terra, 2007.

. (1971) Extensão ou comunicação? Rio de janeiro: Paz e Terra.

Habermas, J. (1995) "Três modelos normativos de democracia" In: Lua Nova - revista de cultura e política. São Paulo: Centro de Estudos de Cultura Contemporânea, (36), 39-53.

Heslin, P. A. , Ochoa, J. G. (2008) Understanding and developing strategic corporate social responsibility. In: Organizational Dynamics. 37(2), 125-144.

Instituto de Tecnologia Social (2004) Reflexões sobre a construção do conceito de tecnologia social. In: Fundação Banco do Brasil, Tecnologia social: uma estratégia para o desenvolvimento, Rio de Janeiro.

Jezine, E.(2004) As práticas curriculares e a extensão universitária. In: Anais do Congresso Brasileiro de Extensão Universitária, 2. Belo Horizonte.

Morin. A.(2004) Pesquisa-ação integral e sistêmica: uma antropedagogia renovada. Rio de Janeiro. DP\&A. 
Mujih, E. (2007) Implementing corporate social responsibility: punishment or compliance? In: Social Responsibility Journal. 3 (3), 79-85.

Muschett, F. D. (org).(1997) Principles of sustainable development. Delray Beach: St. Lucie Press .

Ramminger, T.(maio 2001) Psicologia comunitária X assistencialismo: possibilidades e limites. Psicologia: Ciência e Profissão, 21(1), 42-45. ISSN 1414-9893.

Rede De Tecnologia Social (2006) Fórum Nacional da RTS, 1, Brasília: Abipti.

Rodrigues, I., Barbieri, J.C.( nov./dez. 2008) A emergência da tecnologia social: revisitando o movimento da tecnologia apropriada como estratégia de desenvolvimento sustentável. Revista de Administração Pública. Rio de Janeiro: 42 (6), 1069-94.

Tenório, F.G.(set/out.1998) Gestão social: uma perspectiva conceitual. In: Revista de Administração Pública. 32 (05). Rio de Janeiro, FGV.

\section{FGV.}

.(set/out1998) Gestão social. In: Revista de Administração Pública. 31(4). Rio de Janeiro,

Thiollent, M. (1996) Metodologia da Pesquisa-Ação. São Paulo: Cortez.

Vergara, S.C.(2007) Projetos e relatórios de pesquisa em administração. São Paulo: Atlas, p. 49.

Vieira, M. M. F. (2004). Por uma boa pesquisa (qualitativa) em administração. In: Vieira, M. M. F. e Zouain, D. M. (orgs). Pesquisa Qualitativa em Administração, Rio de Janeiro, Editora FGV.

\footnotetext{
${ }^{\text {i }}$ De acordo com o Instituto de Tecnologias Sociais (ITS Brasil), esta definição de TS resulta de um trabalho conjunto entre mais de 80 instituições - movimentos e organizações da sociedade civil, órgãos do poder público e entidades de ensino e pesquisa. Para tanto, foram realizadas pesquisas sobre o uso do termo Tecnologia Social, mapeamentos de experiências de TS no país e encontros em que se discutiram as práticas das organizações da sociedade civil.
}

Data do recebimento do artigo: 15/06/2011

Data do aceite de publicação: 26/09/2011 